\title{
DIREITO DESPORTIVO: A VISÃO DOS EGRESSOS EM EDUCAÇÃO FÍSICA
}

Flávia Couto FALQUETO flaviafalqueto@ hotmail.com

Chaysther de Andrade LOPES /CAJ-UFG. chaysther-lopes@ hotmail.com

Resumo: Este trabalho tem como objetivo Analisar o conhecimento que os professores egressos da Faculdade de Educação Física (FEF) do Campus Jataí (CAJ) da Universidade Federal de Goiás (UFG), que participam de eventos desportivos com equipes amadoras e escolares, tem do Direito Desportivo. A pesquisa foi realizada com egressos do curso de Educação Física, treinadores ou técnicos de equipes e que estão trabalhando com treinamento desportivo a nível amador com equipes escolares ou não. Os resultados desta investigação poderão contribuir na divulgação da realidade encontrada, propiciando aos futuros e aos atuais profissionais da área do desporto o acesso às informações sobre o direito desportivo e suas responsabilidades na prática de sua profissão. A metodologia utilizada é de cunho qualitativo descritivo, com uma análise temática sobre o assunto. Os sujeitos foram sete professores de Educação Física, egressos do curso FEF/CAJ/UFG, que atuam em escolas públicas e particulares no município. O instrumento de pesquisa foi um roteiro de uma entrevista semi-estruturada, onde a partir dos resultados analisados, três categorias emergiram da realidade investigada: A primeira referiu-se às responsabilidades inerentes ao profissional de Educação Física, a segunda aos procedimentos e normas adotados por aqueles profissionais diante das práticas desportivas, formal e não-formal, e, a terceira abordou o conhecimento sobre o direito desportivo, o acesso a esse conhecimento e sua relevância. Foi possível constatar que o conhecimento acerca do Direito Desportivo demonstrado pelos entrevistados é baseado no senso comum.

Palavras-chave: Direito desportivo; Educação Física; Legislação

Abstract: This paper aims to analyze the knowledge of teachers graduating from the Faculty of Physical Education (FPE) Campus Jataí (CAJ), Federal University of Goiás (UFG), participating in sporting events with amateur and school teams, namely the knowledge those teachers have 
concerning the Sports Law. The research was carried out with graduates of the course of Physical Education, trainers or team coaches, either who work with sports training of amateur teams with school staff or not. The results of this investigation may contribute to divulge the current situation, providing for future and current professionals in the field of sport access to information on sports law, as well as on and their responsibilities in the practice of their profession. The methodology used is of qualitative and descriptive nature, with a thematic analysis on the subject. The participants were seven physical education teachers, graduates of the course FPE / CAJ / UFG who work in public and private schools in the city. The research instrument was a script for a semistructured interview, and based on the results analyzed three categories emerged from the situation investigated: the first one regards the responsibilities inherent to professional physical education, the second one has to do with the procedures and standards adopted by those professionals concerning sporting activities, formal and non-formal, and the third one deals with the knowledge of sports law, access to this knowledge and its relevance. It was possible to verify that the knowledge of the Sports Law demonstrated by interviewees is based on common sense.

Keywords: Sports Law, Physical Education; Legislation

\section{Introdução}

Este trabalho apresenta-se com o intuito de analisar o conhecimento que os professores egressos da $\mathrm{FEF} / \mathrm{CAJ} / \mathrm{UFG}$ que trabalham como treinadores, técnicos de equipes escolares desportivas têm sobre o Direito Desportivo. Assim firma-se a importância desta pesquisa no propósito de demonstrar até que ponto o aprendizado sobre Direito Desportivo exerce influência na vida profissional do professor de Educação Física formado pela $\mathrm{FEF} / \mathrm{CAJ} / \mathrm{UFG}$.

Antes de iniciarmos, é nosso dever para a segurança de todos aqueles que vierem a se interessar pelo estudo deste trabalho ou consulta dos assuntos ora comentados, informar que os textos de lei insertos neste trabalho não substituem os objetos das publicações oficiais. Aqui, estes servem apenas de parâmetro para que se consultem os textos oficiais, por isso, consultem, sempre, as publicações oficiais para ver se as normas citadas estão ou não em vigor. ${ }^{1}$

Diante disto, o presente trabalho também pretende verificar se estes egressos possuem um conhecimento básico sobre Direito Desportivo, se este conhecimento é fruto

\footnotetext{
${ }^{1}$ Para auxílio dos usuários, a consulta aos textos em vigor pode ser feita com o auxílio do site do Governo Federal: www.planalto.gov.br (legislações), lugar onde estas estarão disponíveis e devidamente atualizadas.
} 
dos estudos ocorridos durante o curso de graduação ou de que forma eles adquiriram este conhecimento, e, se a falta deste conhecimento, tem influenciado nos resultados das competições que suas equipes têm participado.

Para a concretização deste trabalho, foi preciso elaborar uma fundamentação teórica sobre o assunto, para em seguida, problematizar nosso estudo no contexto da situação investigada.

O primeiro capítulo busca apresentar os conceitos das palavras direito e desporto, tudo de forma muito particular e pedagógica, já que o tema direito não é tão explorado no âmbito da Educação Física, como quanto o é o desporto. Isso foi possível devido ao fato de a autora deste trabalho ser aluna regular no oitavo período do curso de direito. Entendemos que houve a necessidade de se fazer um tripé entre: a sociedade, o desporto e o direito de forma que, justificasse para o leitor que a junção desses três elementos resultará no direito desportivo, motivo do enfoque deste trabalho.

O segundo capítulo conduz a uma retrospectiva histórica do direito desportivo no Brasil, abordando como se consolidou com o passar do tempo, o nascimento e a necessidade da utilização, do direito desportivo para as práticas desportivas formais e nãoformais como um todo. A abordagem aos itens: a organização da justiça desportiva, as responsabilidades do profissional de Educação Física e a responsabilidade da Universidade como instituição formadora em proporcionar o acesso inicial ao tema, foi extremamente calculada, já que o tema nunca foi explorado antes pelos alunos da graduação, que normalmente desenvolvem pesquisas monográficas ou outras dentro da FEF/CAJ. Todos estes fatos fazem com que nossa postura tenha um cunho ainda maior de informação, motivo pelo qual evitamos ao máximo o uso de meias informações no tocante à utilização das citações legais utilizadas na construção deste trabalho, com vistas sempre à promoção para o conhecimento do tema aos que nunca tiveram contato com ele.

O terceiro capítulo apresenta a metodologia adotada para a concretização do trabalho, bem como o desenvolvimento da pesquisa. Em seguida, está disposta a análise dos dados recolhidos por meio de entrevistas com egressos do curso, selecionados de forma criteriosa, posto que, tivemos a pretensão de encontrar participantes que realmente pudessem colaborar para o resultado final deste projeto.

Entendemos ser de extrema importância que os acadêmicos do curso tenham acesso a essas informações, para terem conhecimento de como este tema é profundo e interfere diretamente na atividade profissional daquele acadêmico que concluir o curso de 
Educação Física e irá inserir-se num mercado de trabalho seleto e ao mesmo tempo competitivo.

\title{
1. Direito e Desporto
}

Inicialmente abordaremos: o direito, a sociedade e o desporto; com vistas a compreender qual a influência desta tríade na origem e evolução do Direito Desportivo, tema central de nossa discussão.

Centramos nossos primeiros estudos em livros de Introdução ao Estudo do Direito de vários escritores, posto que esta disciplina oferece conhecimento sobre três planos: sociológico, filosófico e dogmático, bases gerais para a interpretação do direito. Desta forma também entende AIDAR (2000) quando diz:

\begin{abstract}
Segundo nosso entendimento, a disciplina de Introdução ao estudo do Direito é de cunho filosófico, na medida em que se preocupa com o conhecimento amplo e geral. A disciplina de Introdução ao Direito tem como fulcro o conhecimento real da ciência Jurídica, não apenas no seu aspecto dogmático. Assim, para o conhecimento amplo e geral da ciência do direito, que é a finalidade da cadeira de Introdução ao direito, o estudante deve conhecer a natureza científica de sua ciência (Epistemologia), o seu valor fundamental (Axiologia) e sua inserção na sociedade (realidade social - Sociologia), não se esquecendo do estudo da Ciência Dogmática ou Dogmática Jurídica, [...]. (p. 5)
\end{abstract}

Antes de discorrer e apresentar uma breve evolução histórica do direito é necessário inserí-lo em nosso contexto social. Betioli (2004) entende que para isso, é fundamental a coexistência de três elementos: o homem, a sociedade e o direito, afirmando que é preciso "descobrir o elo que vinculam os três" (p. 19), como se unem e interagem.

\subsection{Sociedade e Direito}

A sociedade é dinâmica, está em constante movimento, evoluindo e convoluindo. Isso se dá devido ao processo de interação que ocorre entre os seres que compõe esse grupo social. Podemos dizer que as pessoas, quando dentro de uma sociedade têm um mesmo objetivo, há uma conjugação de esforços. No entanto, o homem é um ser complexo com interesses e valores que muitas vezes se exteriorizam em forma concorrencial, ou seja, há disputas para excluir um ao outro. Esses conflitos podem ir 
aumentando à medida que não são superados pelo diálogo ou pelos acordos, podendo terminar em agressão ou na interferência do Estado através da Justiça.

Não há vida coletiva se cada indivíduo puder agir como bem entender, guiado pelos seus impulsos e desejos pessoais, sem respeitar os demais. Segundo Beccaria (2004), para a sociedade existir, ela precisa ter meios para controlar seus componentes de forma a minimizar os choques de força e conflito de interesses, nesse sentido seu pensamento sobre os indivíduos é que,

Era necessário protegê-lo contra as usurpações de cada particular, pois, a tendência do homem é tão forte para o despotismo, que ele procura, incessantemente, não só retirar da massa comum a sua parte de liberdade, como também usurpar a dos outros. (p.19)

A citação acima do século XVIII descreve bem a necessidade de termos mecanismos poderosos para sufocar o espírito egoísta do ser humano. Esse controle social se traduz em formas, em comportamentos, dos quais a sociedade se serve para regular a conduta de seus membros em relação ao próximo. Alguns exemplos desses instrumentos de controle social são: a religião, a moral, as regras de trato social e o Direito. Neste sentido também discorre Nader (1982),

Há outros instrumentos de controle social, cada qual em sua faixa própria. A do direito é regrar a conduta social, com vistas à ordem e justiça e somente os fatos sociais mais importantes para o convívio social é que são juridicamente disciplinados. Assim, o direito não visa ao aperfeiçoamento interior do homem; esta meta pertence à moral. Não pretende preparar o ser humano para uma vida supra terrena, ligada a Deus, finalidade buscada pela religião. Nem se preocupa em incentivar a cortesia, o cavalheirismo ou as normas de etiqueta, campo específico das Regras de Trato Social, que procuram aprimorar o nível das relações sociais. (p. 28)

É objetivo do Direito a precisão de suas regras e sanções, visando a certeza e a segurança no comportamento humano, o que certamente não é conseguido pelos outros tipos de controle social. Nader (1982) ainda traz que o Direito dispõe de atributos próprios para efetivar esta precisão, são eles: a) a coercibilidade (possibilidade da repressão ou uso da força); b) o sistema imperativo atributivo (imperativo porque impõe a uma parte o cumprimento de um dever e atributivo porque atribui à outra parte o direito de exigir o cumprimento do dever imposto pela norma); c) a promoção da justiça (virtude de dar a cada indivíduo o que é seu, balizado pelos ideais sociais). 
Aos olhos de Betioli (2004), a sociedade não pode subsistir sem um mínimo de ordem, de direção; deve haver um regramento para orientar, delimitar onde termina a liberdade de um e começa a do outro, dessa maneira o direito procura responder às necessidades de ordem e de justiça da convivência em grupo. A sociedade postula o direito como o meio necessário de subjulgar o homem. Daí a expressão em latim ubis societas, íbis jus, onde há sociedade, aí o direito.

Na conclusão deste autor, homem, sociedade e direito estão intimamente ligados, já que "seus elos se vinculam através do seguinte Silogismo da Sociabilidade $u b i$ homo, ibi societas (onde o homem, aí a sociedade); ubi societas, ibi jus (onde a sociedade, aí o Direito); ubi homo, ibi jus (logo, onde o homem, aí o Direito)” (BETIOLI, 2004, p. $31)$.

A existência da sociedade está condicionada a um mínimo de convivência ordenada e regrada. Assim, para Reale (1994), o direito é o mecanismo que melhor atende a essa exigência de ordenamento das relações sociais, pois impõe regras obrigatórias de comportamento e de organização. $\mathrm{O}$ autor conclui seu pensamento imprimindo duas definições para o direito: a ordenação das relações de convivência ou a disciplina da convivência.

\subsection{Compreensão do termo Desporto}

Para discorrer sobre Direito Desportivo, além de conhecer o termo "Direito" torna-se necessário definir também o que é "Desporto". Neste sentido trazemos à tona qual a semântica da palavra desporto e buscamos esclarecimentos legais sobre o seu conceito e sua abrangência ${ }^{2}$.

Segundo os doutrinadores, há diversos métodos de interpretação (interpretar é descobrir o sentido e o alcance da norma jurídica das normas jurídicas, dentre os quais podemos citar: interpretação gramatical, lógica, sistemática, histórica, sociológica (ou teleológica), a interpretação extensiva e a interpretação restritiva. Da mesma forma, há métodos de integração (adaptar para completar) das normas jurídicas como, por exemplo, a analogia, o costume e os princípios gerais do direito. (DINIZ, 1993, p. 51)

\footnotetext{
${ }^{2}$ Para esta conceituação não recorremos a autores da área de Educação Física que discutem a diferença entre desporto e esporte, e sim embasamento na letra da lei e em dicionários, do que vem a ser desporto, no qual o esporte está inserido como prática desportiva não-formal.
} 
O Desporto Nacional recebeu a devida ordenação legal com a Lei n. ${ }^{\circ} 9.615$ de 24/03/98 ${ }^{3}$, que instituiu as Normas Gerais sobre o Desporto, que foi regulamentada pelo Decreto n. ${ }^{\circ}$ 2.574, de 29/04/98. Aqui o legislador, expressamente obedecendo a classificação Constitucional do artigo 217, apesar de optar apenas pelo termo Desporto teve o cuidado de lhe traçar o âmbito destas práticas dividindo-as em formais e nãoformais, e, o fez dando atenção especial dos intérpretes e aplicadores do direito aos fundamentos constitucionais do Estado Democrático de Direito.

Assim o artigo $1^{\circ}$ (caput) e $\S \S 1^{\circ}$ e $2^{\circ}$, será discutido em partes, visando dar ciência do que vem a ser o conceito da palavra "desporto" e delimitando sua abrangência no país. O caput dispõe: “O desporto brasileiro abrange práticas formais e não-formais e obedece às normas gerais desta Lei, inspirado nos fundamentos constitucionais do Estado Democrático de Direito.” (BRASIL, 1998, s.p.). Na visão de Rodrigues (2004), a citação acima, possui vários significados sendo eles:

1) Delimitar, classificando inicialmente o desporto brasileiro em dois grandes grupos: desporto de prática formal e desporto de prática não-formal.

2) Definir o desporto brasileiro como sendo o de prática formal e não formal.

3) Normatizar o desporto brasileiro por intermédio de lei própria e específica (especial) para toda a atividade desportiva, seja ela formal ou não-formal.

4) Estabelecer, parafraseando o Professor Celso Antonio Bandeira de Mello (citado por Michel Temer), os princípios, as linhas mestras, "os vetores para soluções interpretativas" das questões que envolvam matéria (disciplina) e prática de atividade desportiva (formal e não-formal). (p. 23)

$\mathrm{O} \S$ 1. $^{\circ}$, vem trazendo a exata definição do que vem a ser "prática desportiva formal", "A prática desportiva formal é regulada por normas nacionais e internacionais e pelas regras de prática desportiva de cada modalidade, aceitas pelas respectivas entidades nacionais de administração do desporto" (BRASIL, 1998, s.p.), sendo este, auto explicativo. A entidade nacional de administração do desporto é, por exemplo, a Confederação Brasileira de Basquetebol - CBB, e outras, da mesma natureza.

Já a definição do que vem a ser "prática desportiva não-formal", necessita de uma hermenêutica um pouco mais apurada, vejamos, o $§ 2 .^{\circ}$ diz "A prática desportiva nãoformal é caracterizada pela liberdade lúdica de seus praticantes” (BRASIL, 1998, s.p.). Buscamos a interpretação literal do que vem a ser lúdico, para Houaiss (1980) lúdico ${ }^{4}$ vem

\footnotetext{
${ }^{3}$ A Lei n. ${ }^{\circ}$ 9.615/98, citada em todo este trabalho, comporta as alterações das Leis: Lei no ${ }^{\circ}$ 9.981, de 14/07/00; Lei $n^{\circ}$. 10.264, de 16/07/2001; Lei $n^{\circ}$. 10.672, de 15/03/2003; Lei $\mathrm{n}^{\circ} 10.826$, de 22 de dezembro de 2003 e da Lei n. ${ }^{\circ} 11.118$, de 19/05/2005.

${ }^{4}$ Lúdico - do latim ludus e significa jogar, brincar.
} 
do latim ludus (jogo), e significa jogar, brincar; para Ferreira (2004) lúdico tem o caráter de jogos, brinquedos e divertimentos. Lúdicro ${ }^{5}$ também derivado do latim ludus, para Ferreira (2004) é relativo a jogos, divertimentos, espetáculos públicos.

Destas definições ficamos compelidos a concluir que, na história da semântica do Desporto, este começou por ser lúdico (não-formal) e evoluiu para o lúdicro, que significa espetáculo público e nos leva à competição (formal), e, entendemos que ainda hoje ambos sentidos se mantêm.

$\mathrm{Na}$ intenção de enfatizar o assunto a lei n. ${ }^{\circ}$ 9.615/98 delimitou o entendimento sobre como podem ser reconhecidas as práticas desportivas formais e não-formais. $\mathrm{O}$ artigo $3 .^{\circ}$ aduz que o desporto pode ser reconhecido em três manifestações sendo, a princípio, duas delas não-formal o "desporto educacional” e o "desporto de participação" e uma formal o "desporto de rendimento", este podendo ser organizado e praticado de modo profissional e não-profissional.

\begin{abstract}
Art. $3^{\circ}$ - $\mathrm{O}$ desporto pode ser reconhecido em qualquer das seguintes manifestações: I - desporto educacional, praticado nos sistemas de ensino e em formas assistemáticas de educação, evitando-se a seletividade, a hipercompetitividade de seus praticantes, com a finalidade de alcançar o desenvolvimento integral do indivíduo e a sua formação para o exercício da cidadania e a prática do lazer; II - desporto de participação, de modo voluntário, compreendendo as modalidades desportivas praticadas com a finalidade de contribuir para a integração dos praticantes na plenitude da vida social, na promoção da saúde e educação e na preservação do meio ambiente; III - desporto de rendimento, praticado segundo normas gerais desta Lei e regras de prática desportiva, nacionais e internacionais, com a finalidade de obter resultados e integrar pessoas e comunidades do País e estas com as de outras nações. Parágrafo único. O desporto de rendimento pode ser organizado e praticado: I de modo profissional, caracterizado pela remuneração pactuada em contrato formal de trabalho entre o atleta e a entidade de prática desportiva; II - de modo não-profissional, identificado pela liberdade de prática e pela inexistência de contrato de trabalho, sendo permitido o recebimento de incentivos materiais e de patrocínio. (BRASIL, 1998, s.p.)
\end{abstract}

Estampado no inciso II do caput, igualmente ao Educacional, o desporto de participação merece ser entendido com o mesmo amparo constitucional. Devendo ser incentivado pelo Poder Público, como forma de lazer e como meio de promoção social. Encaixam-se aqui todos os indivíduos que voluntariamente expressem sua vontade de iniciar, dar continuidade ou experimentar mesmo que por curiosidade, uma prática habitual ou esporádica de atividade física, seja ela gratuita ou onerosa.

Rodrigues (2004) especifica que,

\footnotetext{
${ }^{5}$ Lúdrico - do latim ludus e significa espetáculos públicos, competições.
} 
Todas as modalidades desportivas contribuem para a integração dos seus praticantes na plenitude da vida social, pelo simples fato de poder livremente, identificá-lo, mesmo que momentaneamente, com uma forma de lazer, de atividade física e mental capaz de lhe proporcionar determinado prazer, sensação, bem-estar ou, ainda, satisfazer sua vontade. Essa integração social se aprimora à medida que os praticantes desta atividade desportiva se relacionam com outros seguidores da modalidade como acontece, mais fortemente, nos esportes de equipe onde a vitória individual é alcançada com o sucesso do grupo assim como, por exemplo, no voleibol, no basquetebol ou no rafting onde os praticantes da atividade necessariamente, devem agir com sintonia de pensamentos, objetivos e atitudes. (p. 26)

Numa análise geral todas as modalidades desportivas corretamente orientadas e praticadas, podem contribuir tanto para a promoção do bem estar pessoal, prevenindo, protegendo ou recuperando a saúde física, fisiológica ou psíquica dos indivíduos, quanto elevando a auto-estima de seus praticantes. Educação é uma consequiência do desporto ordenado, e, se é certo que o desporto organizado educa, não menos corretos estaremos se afirmarmos que o desporto atua como meio de conscientização e preservação ambiental.

Para finalizar nosso comentário sobre o artigo $3^{\circ}$, seu inciso III dispõe sobre o desporto de rendimento, que tem por objetivo curricular a metodologia técnica do desporto, a formação desportiva dos alunos, a seleção dos melhores atletas, a hipercompetição entre os alunos ou atletas profissionais. As entidades desportivas como as Federações e as Confederações de natureza olímpica visam o desporto de rendimento, porque utilizam as regras de prática desportiva, nacionais e internacionais, com a finalidade precípua de obter resultados, integrar pessoas e comunidades tanto do seu estado como do País quanto, ainda, destes com as nações estrangeiras.

Convém assinalar que constitucionalmente é dever do estado atuar para que o “direito ao desporto" seja uma realidade, para isto é necessário assegurar que a prática desportiva seja democratizada e generalizada, protegendo assim, indistintamente, todas as modalidades desportivas. Ademais, o desporto é a própria sociedade exprimindo-se por meio de regras, relações, objetos, gestos, etc, responsável em alguns momentos, por uma quase união nacional. Neste raciocínio a prática desportiva não pode restringir-se somente ao rendimento, ela necessita de um caráter mais abrangente e permanente de forma a envolver a todos como realização individual ou coletiva.

\section{Procedimentos Metodológicos}

Neste momento apresentaremos a trajetória da pesquisa, desde o surgimento da problemática do trabalho, passando então para escolha e definição do tipo de pesquisa, dos instrumentos de coleta de dados, dos sujeitos e do campo de nossa investigação. Neste 
momento esclarecemos como foi desenvolvido todo este trabalho monográfico, para que possamos enfim, apresentar os dados obtidos em nossa pesquisa.

A proposta deste trabalho é analisar o conhecimento que os professores egressos da FEF/CAJ/UFG que trabalham como treinadores, técnicos de equipes escolares desportivas, tem sobre o Direito Desportivo. Diante disto, pretendemos verificar se estes egressos possuem um conhecimento básico sobre Direito Desportivo, qual a origem deste conhecimento, e, se a falta deste conhecimento exerce influência na vida profissional destes educadores.

Desta forma, o presente estudo é apenas uma amostra, e não pode ser generalizado, para todo e qualquer egresso do curso, desde a sua criação, pois só analisamos as informações coletadas dos egressos que se dispuseram espontaneamente e que se encaixaram na delimitação dos sujeitos da pesquisa.

Pretendemos, com esta investigação, despertar interesses nos acadêmicos e nos docentes do curso, sobre a importância do conhecimento sobre Direito Desportivo no Ensino Superior, como parte integrante do processo de formação do profissional de Educação Física.

Após delimitação do problema e estabelecidos os objetivos propostos da pesquisa, houve a preocupação com a definição da metodologia a ser empregada, para que pudéssemos delimitar os meios pelos quais poderíamos responder ao que estava proposto e que era motivo de nossa investigação.

Constatamos que o tema necessitaria de uma abordagem qualitativa, já que na dedução de Ludke e André (1986, p. 11) permite "o contato direto e prolongado do pesquisador com o ambiente e a situação que está sendo investigada, via de regra através do trabalho intensivo de campo". Segundo Triviños (1987), uma característica da pesquisa qualitativa consiste no fato de que durante os estudos do investigador, este não se preocupa apenas com o resultado e o produto que irá encontrar, mas sim, valoriza todo o processo.

Toda a metodologia foi desenvolvida com base em uma pesquisa descritiva, que segundo Cervo e Bervian (1996, p. 49) "procura descobrir, com a precisão possível, a freqüência com que um fenômeno ocorre, sua relação e conexão com outros, sua natureza e características".

A coleta de dados foi iniciada com um pré-levantamento de questões pertinentes, relevantes e suficientes para a constatação da necessidade da pesquisa, identificação dos possíveis participantes bem como suas áreas de atuação, açambarcando com estes atos, os principais itens necessários à pesquisa exploratória. Para Andrade 
(1997) este é o primeiro procedimento do trabalho científico, tornando possível ao pesquisador a obtenção de maiores informações sobre o assunto o que desencadeará com maior facilidade a pesquisa.

Numa segunda fase do processo exploratório, chegamos a um consenso quanto à delimitação dos possíveis participantes de que seriam profissionais de escolas públicas ou particulares e que deveriam enquadrar-se a alguns critérios. Foram estabelecidos três critérios básicos necessários: $1^{\circ}$ - Foram selecionados treinadores ou técnicos de equipes; $2^{\circ}$ - Deveriam ser egressos da FEF/CAJ/UFG; e $3^{\circ}$ - Que estivessem trabalhando com treinamento desportivo a nível amador seja com equipes escolares ou não. Este procedimento foi adotado por entendermos de grande importância a colaboração que poderiam prestar ao estudo, já que a maioria destes treinadores trabalha com crianças e adolescentes na faixa etária entre os 10 e 17 anos e para estes, o Código Brasileiro de Justiça Desportiva prevê:

\footnotetext{
Art. 162 Os menores de 14 (quatorze) anos são considerados desportivamente inimputáveis, ficando sujeitos à orientação de caráter pedagógico. (ALTERADO)

Parágrafo único. Nos casos de reincidência da prática de atitude antidesportiva por menores de 14 (quatorze) anos, responderá o seu técnico ou representante legal na respectiva competição, caso não tenham sido adotadas as medidas cabíveis para orientar e inibir novas infrações. (ALTERADO) (BRASIL, 2003, s.p.)
}

De posse dos nomes dos possíveis participantes da pesquisa, entramos em contato com os professores previamente selecionados. Inicialmente foram elaboradas as questões da entrevista semi-estruturada, e de acordo com a evolução e a necessidade dentro da entrevista, outras questões foram sendo levantadas.

Todos os professores participantes da pesquisa têm mais de um ano de trabalho com o treinamento de equipes (em escolas particulares e municipais) e todos os anos participam de competições dentro ou fora do município. Este fato para nós tornou-se ímpar, já que, a maioria destas competições possuem regulamentos que deveriam ser do conhecimento destes treinadores.

Para o procedimento da análise de dados, foi utilizada a análise temática. Segundo Bardin (1995), a análise de conteúdo pode ser definida como: 
[...] Um conjunto de técnicas de análise das comunicações visando obter, por procedimentos, sistemáticos e objetivos de descrição do conteúdo das mensagens, indicadores (quantitativos ou não) que permitam a interferência de conhecimentos relativos às condições de produção/percepção (variáveis inferidas) destas mensagens (p. 42).

Após a transcrição das entrevistas, realizamos uma seleção das respostas com vistas a um primeiro enquadramento de seu conteúdo. Surgiram assim pressupostos, palavras-chaves, recortes capazes de proporcionar a categorização do material em questão para posterior análise.

\section{Resultados e Discussões}

3.1 Responsabilidades inerentes ao profissional de Educação Física

Após uma análise profunda entre, as respostas dos participantes com o pensamento de Rodrigues, acerca das responsabilidades deste profissional, concluímos que nossos entrevistados têm um conhecimento superficial de suas responsabilidades como profissional, que aqui eles classificam com sendo "questão de ética" e que nós interpretamos como sendo as responsabilidades adquiridas do "senso comum", inerentes a toda pessoa que vive em sociedade. Chauí (2000), explicita que as características do senso comum apresentam-se como: subjetivos; qualitativos; heterogêneos; individualizadores; generalizadores; estabelecem relações de causa e efeito entre as coisas e entre os fatos; não se surpreendem e nem se admiram com a regularidade, constância, repetição e diferença das coisas; identificam ciência com magia. Pelo senso comum, fazemos julgamentos, estabelecemos projetos de vida, adquirimos convicções e confiança para agir. É baseado em fontes de conhecimento entre as quais o bom-senso, a tradição e a intuição.

Fato este evidenciado quando os participantes, interrogados se possuíam conhecimento de suas responsabilidades, responderam que:

[...] no início do trabalho da atividade física fazemos só os exames iniciais, agora no decorrer do ano das aulas e com o passar do tempo a gente tem os cuidados de relacionamentos pessoais, da integração, de respeitar o limite do outro [...] (p1), [...] Com certeza a gente tem esse conhecimento. Porque esse aluno [...] a partir da educação básica da educação infantil ele vem pra gente e ele vai ser um reflexo da postura do profissional, então a gente tenta assim mediar assim os bons costumes as boas práticas, né, e colocando que participar também é muito importante, não só ganhar a todo custo passando por cima de valores, então a gente tenta passar valores. (p5) 
Compreendemos que os conceitos de responsabilidade profissional, emitidos pelos participantes, partem do bom-senso, da intuição e dos valores que eles possuem e devem repassar, mais pela condição em que estão postos (senso comum), do que pela consciência de suas obrigações como profissionais. Para Aidar (2000), as informações adequadas e claras devem ser dadas para todas as pessoas que forem se envolver com o desporto, sempre. Estas informações deveriam não ser somente verbais, mas de demonstração prática, ou à vista de fotografias, filmagens que detalhem o movimento esperado pelo aluno, as possíveis situações e formas de agir em caso de acidente etc., primando, pela melhor orientação para as atividades desportivas vivenciadas.

O profissional de Educação Física deveria ser capaz de compreender que fazem parte de suas responsabilidades, a obediência às técnicas e as regras do jogo que trabalha. Cabe a ele como professor a obrigação de repassar, preliminarmente ao seu aluno, todas as informações iniciais inerentes à atividade desportiva que será trabalhada.

Pudemos constatar, pelas falas de nossos entrevistados, que ocorrem incentivos equivocados ou incorreta orientação para a exploração da prática desportiva no tocante às suas responsabilidades.

3.2 Procedimentos e normas adotados diante das práticas desportivas, formal e não-formal

Ao analisarmos as respostas de nossos entrevistados, conseguimos perceber que quase todos demonstraram conhecimento de suas responsabilidades, diante desta situação específica, porém ficou evidente que a falta de apoio do estado às escolas públicas é o fator preponderante que faz com que esses profissionais, não atinjam o real êxito em sua profissão. Rodrigues (2004) ainda completa dizendo que, nestes casos, deve imperar o bom senso, a presunção de legitimidade e boa-fé das declarações das pessoas, principalmente, em se tratando de algo que possa vir contra a sua própria incolumidade física ou vida.

Outro dado relevante que verificamos em nossa pesquisa diz respeito à obediência aos procedimento e normas adotados por estes profissionais, uma vez que seis dos entrevistados utilizam-se de autorização familiar para transportar os seus alunos, como veremos à seguir.

[...] a primeira coisa, é a autorização dos pais, a ciência dos pais, eles precisarem saber que os alunos está fazendo aquela atividade, o que ele vai viajar ou que ele vai deslocar, que ele precisa saber, principalmente que os jogos, são no horário de aula, precisa saber que o filho esta perdendo, deixando de assistir a aula [...] (p3) 
[...] agente procura fazer aqui na escola uma autorização colocando (pausa) para que esse aluno vá, normalmente são de menores, que tragam já a autorização dos pais ou responsável já colocando o que que vai ser feito, onde vai ser jogado, eu sempre procuro passar os horários para que os pais estejam a par, por que já tive experiências passadas, problemas por que a gente não avisou o horário, o aluno deixou o jogo e você nem sempre pode levá-lo em casa, [...] (p7)

O profissional de Educação Física precisa sempre ater-se à discriminação legal, quando atuar junto aos absolutamente incapazes e aos relativamente incapazes.

A Lei 10.406/2002 - Código Civil, no seu artigo $3^{\circ}$, classifica que são absolutamente incapazes de exercer pessoalmente os atos da vida civil, ou seja, não podem assumir responsabilidades por seus atos, e se assumirem estes atos não terão validade: os menores de 16 (dezesseis) anos; os que, por enfermidade ou deficiência mental, não tiverem o necessário discernimento para a prática desses atos; e, os que, mesmo por causa transitória, não puderem exprimir sua vontade. Os relativamente incapazes, compreendem dentre outros, aqueles que têm idade entre 16 e 18 anos.

Portanto, podemos inferir que conforme já foi citado, caberá aos profissionais que estiverem acompanhando estes menores, a responsabilidade por qualquer ato praticado por estes, incluindo os deveres de vigilância e de cuidado. Aidar (2000) reforça nossa conclusão aduzindo que, quem consente validamente por essas pessoas são os seus representantes legais (pais, tutores, curadores etc). Quando essas pessoas, absolutamente incapazes, não tiverem representantes legais, ou forem maiores de dezesseis anos, o Juiz de Direito lhes dará curador especial. Há, em princípio, a substituição da vontade das citadas pessoas pela vontade dos seus representantes legais.

3.3 O conhecimento sobre o direito desportivo, o acesso a esse conhecimento e sua relevância

Concordamos com Coelho (1996), quando afirma que a Universidade é um local em que se privilegia, antes de tudo, a transmissão do saber já consagrado, criadora de novos saberes, além de ser uma instituição investigadora, com estímulo à curiosidade, à ousadia e à iniciativa. Para o referido autor, a Universidade está inserida em uma realidade histórica, política e social e cabe a ela atuar e intervir neste contexto.

Constatamos nas grades curriculares da instituição formadora dos participantes da nossa pesquisa que a mesma, em momento nenhum, contemplou o tema gerador de nossa pesquisa. Desta forma, podemos relatar que o artigo $2^{\circ}$ da resolução CCEP $n^{\circ} 393$, demonstra que o licenciado de Educação Física deve ser capaz de "dominar os conteúdos 
fundamentais e metodológicos inerentes à área" (UFG, 1995, p.1). Analisando o artigo em questão podemos concluir que, se o tema tratado neste trabalho é de fundamental importância, (como bem disse um de nossos entrevistados); se o direito desportivo faz parte de todo o contexto da vida profissional da pessoa formada neste curso; e, se conhecer suas responsabilidades legais é um meio de se prevenir durante o exercício de sua profissão; então, podemos afirmar, com toda certeza e convicção, que a universidade é o primeiro lugar que deveria proporcionar o conhecimento sobre direito desportivo.

O conhecimento acerca do direito desportivo pode proporcionar aos profissionais de Educação Física, um aparato de proteção e uma conseqüente tranqüilidade, posto que, sentindo-se amparado por lei, este profissional poderá exercer sua profissão com maior segurança. Esta foi a conclusão que chegamos diante da fala de um dos sujeitos que disse:

\begin{abstract}
Eu acho que se existe posições legais que regulamentam, esse relacionamento do professor-aluno, nesse aspecto é muito mais fácil, porque eu posso me recorrer sempre a isso, eu tenho um parâmetro para resolver os meus problemas, eu não ficaria só no âmbito do instinto de proteção, eu acho que o instinto ele é bonito, ele é preciso, mas ele fica só no canto do romântico, ai quando você falou, eu achei interessante, eu posso ás vezes tá ultrapassando, colocando uma sobrecarga nas minhas costas, que não seria necessário, ás vezes to deixando de lado alguma coisa que seria mais importante, então acredito que se existe esses parâmetros, eu acho que é super positivo. (p4)
\end{abstract}

A lei 9.615/98 tantas vezes comentada neste trabalho, traz em um de seus artigos os princípios gerais do desporto, nos quais os profissionais que trabalham com o desporto deveriam se pautar para proceder de forma legal em sua profissão.

Art. 2o O desporto, como direito individual, tem como base os princípios:

I - da soberania, caracterizado pela supremacia nacional na organização da prática desportiva;

II - da autonomia, definido pela faculdade e liberdade de pessoas físicas e jurídicas organizarem-se para a prática desportiva;

III - da democratização, garantido em condições de acesso às atividades desportivas sem quaisquer distinções ou formas de discriminação;

IV - da liberdade, expresso pela livre prática do desporto, de acordo com a capacidade e interesse de cada um, associando-se ou não a entidade do setor;

$\mathrm{V}$ - do direito social, caracterizado pelo dever do Estado em fomentar as práticas desportivas formais e não-formais;

VI - da diferenciação, consubstanciado no tratamento específico dado ao desporto profissional e não-profissional;

VII - da identidade nacional, refletido na proteção e incentivo às manifestações desportivas de criação nacional;

VIII - da educação, voltado para o desenvolvimento integral do homem como ser autônomo e participante, e fomentado por meio da prioridade dos recursos públicos ao desporto educacional;

IX - da qualidade, assegurado pela valorização dos resultados desportivos, educativos e dos relacionados à cidadania e ao desenvolvimento físico e moral; 


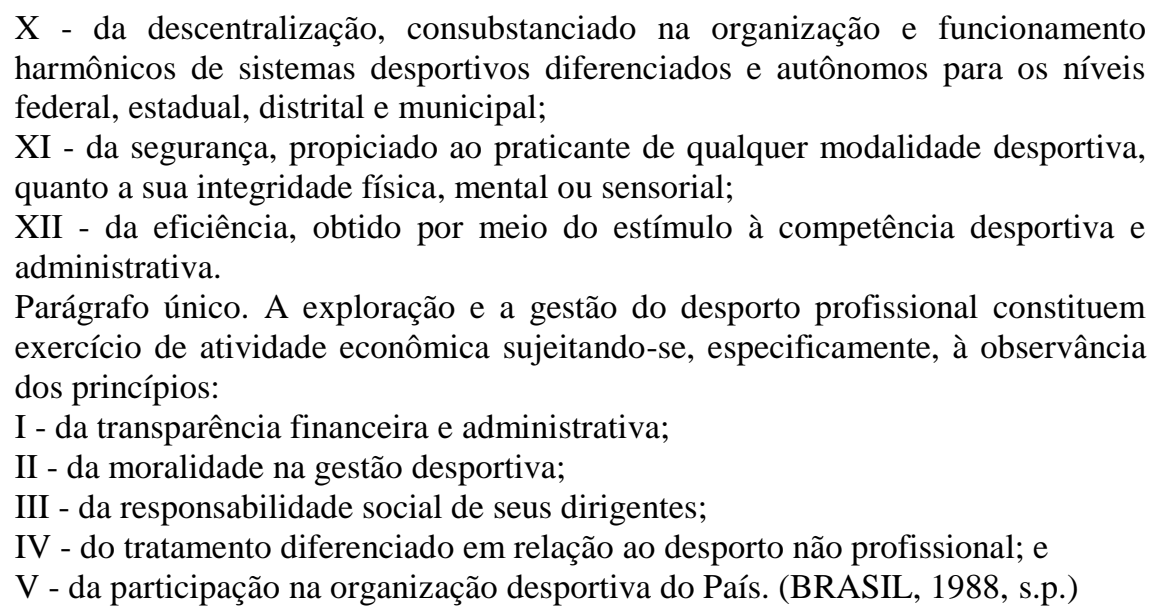

A Lei não é apresentada ao cidadão como acontece com as propagandas de televisão. É necessário que cada profissional que sinta necessidade de um maior conhecimento das leis inerentes à sua profissão, procure na própria lei do desporto o que lhe falta, embasando suas práticas nos princípios gerais do desporto, o que lhe proporcionará um mínimo de segurança dentro do seu exercício profissional. Apontar a instituição formadora como a culpada por sua desinformação também não é a saída. À Universidade cabe apenas a conscientização da necessidade e da abrangência que este tema tem, na vida do profissional que ela prepara para o mercado de trabalho. Contudo a ciência evolui, os equipamentos digitais de ginástica de hoje não são iguais aos equipamentos manuais de dez anos atrás, a própria tecnologia obriga o profissional a atualizar-se para permanecer em atividade. A evolução tecnológica imprime um avanço da sociedade, esta cada vez mais exigente e conhecedora de seus direitos, acaba por assumir um papel de juiz, e a ela caberá uma seleção natural, permanecendo no mercado de trabalho o profissional que melhor atender a estas novas exigências.

Constatamos pelas entrevistas que apenas um entrevistado tinha "ouvido falar" do tema, antes que a entrevistadora o procurasse, os demais deixaram evidente que tomaram conhecimento do assunto no primeiro contato que tiveram com a pesquisadora: "Depois que eu conversei com você, descobri que eu não tenho conhecimento sobre Direito Desportivo (p4)"; "Nenhum, só se você começar a falar aí, a não ser isso, mas eu não conhecia [...] (p7)”; “[...] não nenhuma disciplina. Só depois de conversar com você (p6)".

Tais alegações perante um juiz, diante de um caso concreto como o que descreve Rodrigues (2004), não livrará este profissional da responsabilização pelo fato. 
Responsabilidade Civil - Faculdade de Educação Física - Morte de aluno no curso de aula de natação - Método arriscado de ensino - Culpa do professor Responsabilidade solidária da Universidade, Segunda ré. [...] Responsabilidade Civil. Acidente ocorrido com vítima, aluna de Educação Física, no curso de aula de natação ministrada durante o currículo regular da faculdade, do qual resultou a morte da vítima. Culpa do professor na utilização de método de mergulho na parte rasa da piscina, na passagem no interior de um bambolê, utilizável em prática de participantes à disputa de provas. Impropriedade do método. Culpa concorrente da univerdidade, in eligendo $e$ in vigilando (TJRJ $-2^{\mathrm{a}} \mathrm{C}$. - Ap. Rel. Penalva Santos - J. 6.11.84 - RT 597/173). (p.229, grifo nosso)

Muitos outros aspectos poderiam ser citados sobre o direito desportivo, evidenciando que ainda existe uma vasta área sobre este assunto a ser explorada. Apresentamos dados que demonstram de que forma acontece a responsabilidade do profissional de Educação Física, as medidas de segurança que este profissional pode tomar para salvaguardar seu trabalho, a forma como se dá o conhecimento sobre o direito desportivo, o acesso a esse conhecimento e a relevância deste tema para o exercício da função de Educador Físico. Concluímos que foi feito muito pouco, e ainda resta muito a fazer. O conhecimento, seja ele de qualquer categoria, deve ser canalizado, construído e reconstruído constantemente por meio de pesquisas e novas descobertas, principalmente se estas novas descobertas puderem contribuir para a formação de um profissional mais completo.

\section{REFERÊNCIAS BIBLIOGRÁFICAS}

AIDAR, Carlos Miguel Castex. Direito Desportivo. Campinas SP: Editora Mizuno, 2000.

ANDRADE, Maria Margarida de. Introdução à metodologia do trabalho científico: elaboração de trabalhos na graduação. São Paulo: Atlas, 1997.

BARDIN, Laurence. Análise de conteúdo. Trad. Luís Antero Reto e Augusto Pinheiro. Lisboa: Edições, 1995.

BECCARIA, Cesare. Dos Delitos e Das Penas. Tradução Torrieri Guimarães. SP: Editora Martin Claret, 2004.

BETIOLI, Antonio Bento. Introdução ao Direito: Lições de Propedêutica Jurídica Tridimensional. SP: Editora Letras e Letras, 2004. 
BRASIL. Constituição da República Federativa do Brasil. De 05/10/1988. Disponível em www.planalto.gov.br, acesso em 20/08/2007.

BRASIL. Lei n ${ }^{\circ}$ 10.406, de 10/01/2002. Código civil. Disponível em www.planalto.gov.br, acesso em 20/08/2007.

BRASIL. Resolução CNE nº 1, de 24 de dezembro de 2003, com alterações da Resolução n 11-MEC-CNE de 29 de março de 2006. Código Brasileiro de Justiça Desportiva, (Texto Consolidado) aplicável às entidades componentes do Sistema Nacional do Desporto (Entidades privadas: Confederações, Federações, Ligas, Clubes, Associações, etc). Diário Oficial [da República Federativa do Brasil]. Brasília, pág. 182, 24 dez. 2003, republicada, em parte, no D.O.U. - p. 98, 29 dez. 2003. Seção 1. Publicadas as alterações, no D.O.U. p. 120, 31 mar. 2006. Disponível em www.planalto.gov.br, acesso em 20/08/2007.

BRASIL. Lei $\mathrm{n}^{\circ}$ 9.615, de 24 de mar. de 1998. Institui normas gerais sobre desporto e dá outras providências. Brasília, 24 de março de 1998; $177^{\circ}$ da Independência e $110^{\circ}$ da República. Brasília, 14 de julho de 2000; 179o da Independência e 112o da República. Alterada pelas leis leis $n^{\circ}$ 9.940/99, $n^{\circ}$ 9.981/2000, $n^{\circ}$ 10.264/ 2001 e MP. $n^{\circ}$ 2.123-29, 23.02.2001, MP no 2.141/23.03.2001, MP 2.193-6/23.08.01. Diário Oficial [da República Federativa do Brasil]. Brasília, p. 01, 24 mar.1998. Disponível em www.planalto.gov.br, acesso em 20/08/2007.

BRASIL. Lei $n^{\circ}$ 9.696, de 01 de setembro de 1998. Dispõe sobre a regulamentação da Profissão de Educação Física e cria os respectivos Conselho Federal e Conselhos Regionais de Educação Física. Diário Oficial [da República Federativa do Brasil]. Brasília, p. 01, 02 set.1998. Seção 1. Disponível em www.planalto.gov.br, acesso em 20/08/2007.

CERVO, Amado Luiz; BERBIAN, Pedro Alcino. Metodologia científica. São Paulo: Makron books, 1996.

CHAUÍ, Marilena. Convite à Filosofia. São Paulo. Ática, 2000.

COÊLHO, Ildeu Moreira. Formação do educador dever do estado, tarefa da universidade. In: BICUDO, Maria Aparecida Viggini; SILVA JÚNIOR, Celestino Alves da (Orgs.). 
Formação do Educador: dever do estado, tarefa da universidade. São Paulo: Editora da Universidade Estadual Paulista, 1996. p. 17 - 43.

DINIZ, Maria Helena. Curso de Direito Civil Brasileiro. S.P: Saraiva, 1993.

FERREIRA, Aurélio Buarque de Holanda. Novo Dicionário Eletrônico Aurélio versão 5.0 - . Curitiba PR: Editora Positivo, 2004.

HOUAISS, Antonio. Dicionário Enciclopédico Koogan Larousse. RJ: Larousse do Brasil, 1980.

LÜDKE, Menga; ANDRÉ, Marli E. D. A. Pesquisa em Educação: abordagens qualitativas. São Paulo: EPU, 1986. p. 11 e 38.

NADER, Paulo. Introdução ao Estudo do Direito. RJ: Forense, 1982.

TRIVIÑOS, Augusto Nibaldo Silva [et al.]. A pesquisa qualitativa na Educação Física: Alternativas metodológicas. 2. ed. - Porto Alegre: Editora da UFRGS/Sulina, 2004.

REALE, Miguel. Teoria Tridimensional do Direito. São Paulo: Saraiva, 1994.

RODRIGUES, Hélder Gonçalves Dias. A responsabilidade civil e criminal nas atividades desportivas. Campinas SP: Servanda, 2004. 